\title{
Coronavirus Pandemic - \#STAYHOME: How Are You Holding Up? Questions And Tips For 11-18 Year Olds To Make It Better
}

\section{Dóra Szentiványi}

Eotvos Lorand Tudomanyegyetem

\section{Lili Olga Horváth}

Eotvos Lorand Tudomanyegyetem

\section{Anne Kjeldsen}

Bjorknes Hoyskole

Kirsten L Buist

Universiteit Utrecht

\section{Bernadett Frida Farkas}

Semmelweis Egyetem Doktori Iskola

\section{Gyöngyvér Ferenczi-Dallos}

Eotvos Lorand Tudomanyegyetem

\section{Péter Garas}

Semmelweis Egyetem Doktori Iskola

\section{Dóra Gyốri}

Eotvos Lorand Tudomanyegyetem

Ágnes Győrfi

freelancer

\section{Dóra Győ̃rfi}

Institute Seni Indonesia Surakarta

Judit Balazs ( $\sim$ judit.agnes.balazs@gmail.com )

ELTE, PPK, Psychology Institute

\section{Study protocol}

Keywords: COVID-19 pandemic, restrictions, adolescent, mental health, quality of life, online prevention program

Posted Date: May 18th, 2020

DOl: https://doi.org/10.21203/rs.3.rs-29381/v1 
License: (c) (i) This work is licensed under a Creative Commons Attribution 4.0 International License. Read Full License 


\section{Abstract}

Backgrounds. Adolescents have to cope with several challenges and restrictions due to the COVID-19 pandemic, with many of those incongruent with the typical developmental tasks of adolescent age. Some adolescent might be particularly vulnerable in this situation, including those who are deprived of psychological, social or health care services and/or are exposed to abuse or neglect in their home environment.

The aims of the current international multicentre follow-up study are to: 1 . collect data on the mental health and quality of life of adolescents during and after the pandemic; 2 . improve their mental health by providing an online prevention program that addresses their actual needs on a weekly basis; 3 . accelerate the development of culturally adapted prevention programs by involving an international team, and 4 . to contribute to adequate preparation for any potentially occurring, similar situation in the future.

Methods. Participants aged 11-18 years and their parents/caregivers from different parts of Europe and non-European countries are recruited online. Data are collected on a weekly basis by means of structured self-administered online questionnaires on adolescents' mental health, quality of life and current attitudes and needs. The prevention program is developed and provided based on the continuously analysed incoming data.

Discussions. Prevention based on the results of the study is expected to contribute to maintaining adolescents' mental health, improve their quality of life, increase their and their environment's cooperation with the necessary restrictions during the pandemic, and to make reintegration easier once the restrictions are over. Furthermore, the study has the potential to inform on the wellbeing of children and adolescents in extreme situations in general, thus contribute to future preventive measures and policymaking.

\section{Background}

Since the coronavirus disease (COVID19) outbreak, most countries ask people to isolate themselves at home. Children and adolescents have to cope with several restrictions due to COVID-19 as well, including separation from loved ones, friends, distance learning, loss of having leisure activities. As a recent systematic literature review on the psychological impact of restrictions during previous major infectious disease outbreaks shows all these can lead in longer restrictions duration to unpleasant experiences, e.g. boredom, frustration, and anger (Brooks et al, 2020).

Adolescence is considered a normative crisis even for those with healthy development (Erikson, 1968). Adolescents face many bio-psycho-social changes and new challenges, including becoming independent from the family and exploring various domains of identity (Goud, 2003; 2009). Thus, coping with the current situation and cooperating with the restrictions can be hard for adolescents - and their environment -, since these circumstances can be experienced as a situation incongruent with their developmental tasks. 
Children and adolescents often present with symptoms of more than one condition and sometimes the symptoms overlap. The quality of home and social educational environments influence children's and adolescents' wellbeing and functioning. Exploring and addressing psychosocial stressors along with opportunities to activate supports are critical elements of the assessment and management plan.

Although behavioural and emotional symptoms of varying levels of severity are very common in the general population, the diagnoses of behaviour and emotional disorders - which are umbrella terms of several disorders - include only children and adolescents with a moderate to severe degree of psychological, social, educational or occupational impairment. Behaviour disorders are characterized by increased levels of hyperactivity, aggression, impulsivity, while emotional disorders are characterized by increased levels of anxiety, depression, fear, and/or somatic symptoms (World Health Organization, 2016).

These psychological impact of the restrictions can decrease its benefits. Previous studies showed that having a good understanding of the reasons for restrictions, reducing the boredom and improving the communication can mitigate the negative psychological consequences of the restrictions (Brooks et al, 2020), such as elevated levels of emotional and behavioural problems as well as lower perceived quality of life.

Quality of life is a multidimensional concept that includes the physical, social, and emotional components of health (World Health Organization, 1993), which can be an important outcome measure for understanding the impact of a psychological distress on children and adolescents suffering from the consequences of the pandemic.

Moreover, some children can become particularly vulnerable, even beyond the aforementioned challenges. Many of those in need for psychological, social or health care are now partly or completely deprived of these services. Children who are exposed to domestic abuse or neglect are at increased risk during these times.

Based on previous experiences of major infectious disease outbreaks, when quarantine was a necessary preventive measure, providing information, support and meaningful activities for people who undergo to the restrictions can thus be crucial to maintain their mental health and to increase their cooperation with the regulations related to tackling the spread of the pandemic. As described above, children and adolescents currently have to face several restrictions and specific challenges due to the COVID-19 pandemic.

During this global pandemic, countries are dealing with the restrictions differently. They vary in the severity of restrictions (e.g., complete lock-down versus social distancing; schools open versus closed), in the onset and length of the restrictions (e.g., two weeks versus a month following the first COVID-19 case), and in communication surrounding the restrictions (e.g., daily versus weekly government updates). 
Therefore, the current longitudinal cross-national online research project and targeted prevention program, entitled "Coronavirus pandemic - \#stayhome: How are you holding up? Questions and tips for 11-18 year olds to make it better" is designed to monitor and support children and adolescents and their families/caregivers during and after COVID-19 pandemic.

\section{Methods/design}

The objectives of the current study are:

- to monitor the mental health and quality of life of children and adolescents and collect data on their specific challenges and needs during the pandemic;

- to compare mental health, quality of life, and specific challenges and needs of children and adolescents across different countries (e.g. Hungary, Norway, The Netherlands);

- to support children and adolescents in coping with the current situation in a constructive way: to reduce the unpleasant psychological experiences and improve their mental health by providing a targeted online prevention program that reflects their actual needs on a weekly basis;

- to facilitate the sharing of good practices through the involvement of international experts, thus accelerating the development of prevention;

- to contribute to adequate preparation for any potentially occurring, similar situation in the future.

\section{Centres and Ethics}

The study entitled "Coronavirus pandemic - \#stayhome: How are you holding up? Questions and tips for 11-18 year olds to make it better" is an international multicentre study. The coordinating centre of the study is the Research Group of Childhood Mental Disorders of the Institute of Psychology, Eotvos Lorand University (ELTE), Budapest, Hungary. Other, already participating sites are the Utrecht University, Utrecht, Netherlands and the Bjorknes University College, Oslo, Norway. Further centres are under involvement, i.e. from Austria and Indonesia. The study is still open for other participating countries.

The multicentre study, with all sub-centres included, has been approved by the ethical committee at the Institute of Psychology ELTE, Budapest (Ethical permission number: 2020/144, dated 31/03/2020). Furthermore, ethical approval is obtained from each site's local ethics committee.

The study logo is designed for the project and translated to all participating languages. Currently it is available in English, Hungarian, Dutch and Norwegian (see Fig. 1, Fig. 2, Fig. 3, Fig. 4).

Please insert Fig. 1. here

Please insert Fig. 2. here

Please insert Fig. 3. Here 


\section{Participant and Procedure}

Children and adolescents aged 11-18 years and their parents/caregivers from different parts of Europe and non-European countries are recruited. After written informed consent of the parents/caregivers and the children and adolescents (under 16 or 18 years, respectively, according to national legislation) and the youngsters only (above 16 or 18-19 years, respectively), the questionnaire is distributed online.

The following text is used for online recruitment by posting it on the respective institution's official web pages and Facebook pages: "\#stayhome: How are you holding up? Questions and tips for 11-18-year olds to make it better. Do you have 10 minutes to help yourself and others? If you do, please fill out our questionnaire and we will share useful materials about how to improve your physical and mental health and other exciting topics."

Further distribution happens through snowball sampling as it will be spread among the target groups through various public and social media channels. The target baseline sample is a minimum of 300 children and adolescents in each participating country. The baseline evaluation questionnaire is followed up weekly to study changes in mental health, quality of life and attitudes of children and adolescents during the coronavirus disease pandemic. Data are collected by means of structured questionnaires (see below).

The time frame of the study is set to one year from study start. Thus, the study will be running while the participants are experiencing restrictions due to the COVID-19 and likely also after the restrictions may have been reduced or removed depending on the development of the pandemic and on national policies.

\section{Measures}

Children and adolescents and their parents/caregivers administer a self-report questionnaire that includes well-established measures and items developed for the current study.

Mental health. The Strengths and Difficulties Questionnaires (SDQ) is used to evaluate the mental health of children and adolescents. It is a brief screening instrument, consisting of 25 items and 5 subscales: Emotional Symptoms, Conduct Problems, Hyperactivity, Peer Relationship Problems, Prosocial Behaviour (Goodman, 1997). All the scales together, except the prosocial scale, form the SDQ Difficulties scale. The total difficulties score is generated by summing scores of the four difficulty scales. Participants are asked to indicate how true different statements are describing behaviour and feelings ( $1=$ not true, $2=$ somewhat true, and $3=$ certainly true). Higher scores indicate higher level of mental health impairment. The extended version of the SDQ is used in the current study, which includes an impact supplement, a measure of functional impairment (Goodman, Meltzer, \& Bailey, 1998). Both the self-report and the parentreport versions of the SDQ are used. 
Quality of life. Quality of life of children and adolescents was measured by the Inventar zur Erfassung der Lebensqualität von Kindern und Jugendlichen (ILK) scale (Mattejat and Remschmidt, 1998; Kiss et al., 2007). The ILK scale evaluated six domains of quality of life: school, family, peer relations, time spent alone, somatic and mental health, and general QoL using seven items. ILK use a 5-point Likert scale (from $1=$ less impairment to $5=$ the most serious impairment) for the evaluation of the items. High scores indicate low levels of QoL. Both the self-report and the parent-report versions of ILK are used.

Additional questions. Questions designed for the study: demographic data and guided questions on the participants' fields of interests and the effects the pandemic has on their psychosocial needs and everyday life.

The questionnaire follows a branching structure, so it does not burden the respondents unnecessarily; completing it takes approximately 15 minutes the first time and 10 minutes at all follow-up occasions. We use the same above described questionnaires during baseline and follow up evaluations, except a few basic not-changeable demographic data are asked only at the baseline.

\section{Prevention Program}

As highlighted by Brooks et al. (2020) in their recent systematic literature review on the psychological impact of restrictions during previous epidemics, lack and/or inadequate information, boredom and reduced motivation are related to mental distress. Based on this, to support children and adolescents to cope in a constructive way with their current situation during COVID19 pandemic, weekly prevention programs are sent to each participant. As data are analyzed parallel with data collection, the prevention program can continuously reflect on the current needs of the participants. The program consists of the followings:

- general information on how to improve mental health,

- informational about crises hotlines and online platforms,

- specific information focusing on a weekly mental health topic, based on the results of the current week delivered to participants through a letter with a personal tone, an illustration designed for the weekly topic, and a video message by a popular person (e.g. singer, actor),

- a personalized and culturally adapted selection of links related to activities that the participant has responded that she/he would like to receive materials about, - social media platforms where the key messages of the prevention program are delivered, to reach and support adolescents beyond those involved directly in the study.

\section{Data Handling And Security}

Data is collected anonymously and in line with the General Data Protection Regulation (GDPR). The participants are guided on how to create a personal id-code that is used throughout the study to identify 
each participant to ensure anonymity. E-mail-addresses are also requested for follow-up. Email addresses are stored separately from the participants answers and only the dedicated researchers of each study centre have access to it.

Data collection is handled through the Qualtrics XM online platform technology, which is fully GDPR compliant and ISO certified, implying strong encryption under transfer, storage and accessing of data. The server is physically located within the EU (in Brussels). Only the Qualtrics licence holder can access the data on the server. Each study sites hold separate Qualtrics licences, and data from the various sites are thus stored separately from another. Only data in anonymised form (i.e. with id-code only and with no e-mail addresses attached) will be transferred to the coordinating centre of the multicenter study to allow for analyses on the pooled data set.

\section{Financing}

The multisite study is an ad-hoc project tailored to the unexpected situation of the Covid-19 pandemic. There is no public financing of the study now apart from covering of running expenses by the hosting institutions and the regular payroll of researchers. Applications for study financing will be sent to appropriate funding agencies.

\section{Discussion}

Weekly follow-up data contributes to design online intervention programs to children and adolescents that continuously reflect on their actual needs for a one-year period after the outbreak of COVID-19 pandemic. This shall contribute to maintaining their mental health and social support network, and reducing their boredom, frustration, and anger. This is also expected to increase their and their environment's cooperation with the necessary restrictions, and to make reintegration easier once the restrictions are over.

The rationale for the one year time frame of the study is to gain knowledge on child and adolescent mental health and wellbeing while the children and adolescents are experiencing restrictions due to COVID-19 and likely also after the restrictions, mapping the consequences that it may have for them due to possible impacts on for instance family economy and living conditions.

Moreover, resulting knowledge may benefit health authorities and policymakers - who are in charge for funding of mental health preventive efforts and interventions of clinicians working with children and adolescents regionally, nationally and internationally - by giving insight into the mental health and wellbeing of children and adolescents in several European and non-European countries during the ongoing pandemic.

The study is expected to provide important information week to week and shed light on changes in these domains across time and countries. The data also has the potential to inform on the wellbeing of children 
and adolescents in extreme situations in general, thus contribute to preventive measures in the future.

A social media campaign, e.g. involving celebrities popular among adolescents will be organized to ensure visibility for the project. Results based on the continuously analysed data will also be disseminated through the media to reach public interest.

\section{Abbreviations}

COVID19

coronavirus disease

ELTE

Eotvos Lorand University

GDPR

General Data Protection Regulation

ILK

Inventar zur Erfassung der Lebensqualität von Kindern und Jugendlichen

SDQ

Strengths and Difficulties Questionnaires

\section{Declarations}

\section{Ethics approval and consent to participate}

The multicentre study, with all sub-centres included, has been approved by the ethical committee at the Institute of Psychology ELTE, Budapest (Ethical permission number: 2020/144, dated 31/03/2020). Furthermore, ethical approval is obtained from each site's local ethics committee.

\section{Consent for Publication}

Not Applicable

\section{Availability of data and materials}

Not applicable

\section{Competing interests}

The authors declare that they have no competing interests" in this section. 


\section{Funding}

The multisite study is an ad-hoc project tailored to the unexpected situation of the Covid-19 pandemic. There is no public financing of the study now apart from covering of running expenses by the hosting institutions and the regular payroll of researchers. Applications for study financing will be sent to appropriate funding agencies.

\section{Authors' contributions}

All co-authors participated sufficiently in the work to take public responsibility for all or part of the content, AND have made substantive intellectual contributions to the submitted manuscript in the form of, i.e. DSz: 1) conception and design, 2) revising it critically for important intellectual content; LOH: 1) conception and design; 2) revising it critically for important intellectual content, AK: 1) conception and design, 2) revising it critically for important intellectual content; KLB: 1) conception and design, 2) revising it critically for important intellectual content; BFF: 1) conception and design, 2) revising it critically for important intellectual content; GyFD: 1) conception and design, 2) revising it critically for important intellectual content; PG: 1) conception and design, 2) revising it critically for important intellectual content; DGyf: 1) conception and design, 2) revising it critically for important intellectual content; AGy: 1) design, 2) revising it critically for important intellectual content; DGy: 1) conception and design, 2) revising it critically for important intellectual content; and JB: 1) conception and design; 2) drafting the article. All authors approved the submitted version; AND agreed both to be personally accountable for the author's own contributions and ensured that questions related to the accuracy or integrity of any part of the work, even ones in which the author was not personally involved, are appropriately investigated, resolved, and the resolution documented in the literature.

\section{Acknowledgement}

Not Applicable

\section{References}

1. Brooks SK, Webster RK, Smith LE, Woodland L, Wessely S, Greenberg N, Rubin GJ. The psychological impact of quarantine and how to reduce it: Rapid review of the evidence. Lancet. 2020;395:912-20. doi:10.1016/S0140-6736(20)30460-8.

2. Erikson EH. Identity: Youth and crisis. New York: Norton \& Company Inc; 1968.

3. Goodman R. The Strengths and Difficulties Questionnaire: A research note. J Child Psychol Psychiatry. 1997;38:581-6. doi:10.1111/j.1469-7610.1997.tb01545.x.

4. Goodman R, Meltzer H, Bailey V. The Strengths and Difficulties Questionnaire: A pilot study on the validity of the self-report version. European Child Adolescent Psychiatry. 1998;7:125-30. 
doi:10.1007/s007870050057.

5. Gould MS, Greenberg T, Velting DM, Shaffer D. Youth suicide risk and preventive interventions: A review of the past 10 years. Journal of the American Academy of Child Adolescent Psychiatry. 2003;42:386-405. doi:10.1097/01.CHI.0000046821.95464.CF.

6. Gould MS, Marrocco FA, Hoagwood K, Kleinman M, Amakawa L, Altschuler E. Service use by at-risk youths after school-based suicide screening. Journal of the American Academy of Child Adolescent Psychiatry. 2009;48:1193-201. doi:10.1097/CHI.0b013e3181 bef6d5.

7. Mattejat F, Remschmidt H. Zur Erfassung der Lebensqualität bei psychisch gestörten Kindern und Jugendlichen - Eine Übersicht. Zeitschrift für Kinder Jugendpsychiatrie Psychotherapie. 1998;26:183-96.

8. World Health Organization. Measurement of quality of life in children: Report of a WHO/ IACAPAP Working Party. London: World Health Organization; 1993.

9. World Health Organization. (2016). mhGAP intervention guide for mental, neurological and substance use disorders in non-specialized health settings: mental health Gap Action Programme( $m h G A P)$-version 2.0. World Health Organization.

\section{Figures}




\section{\# STAYHOME}

How are you holding up?

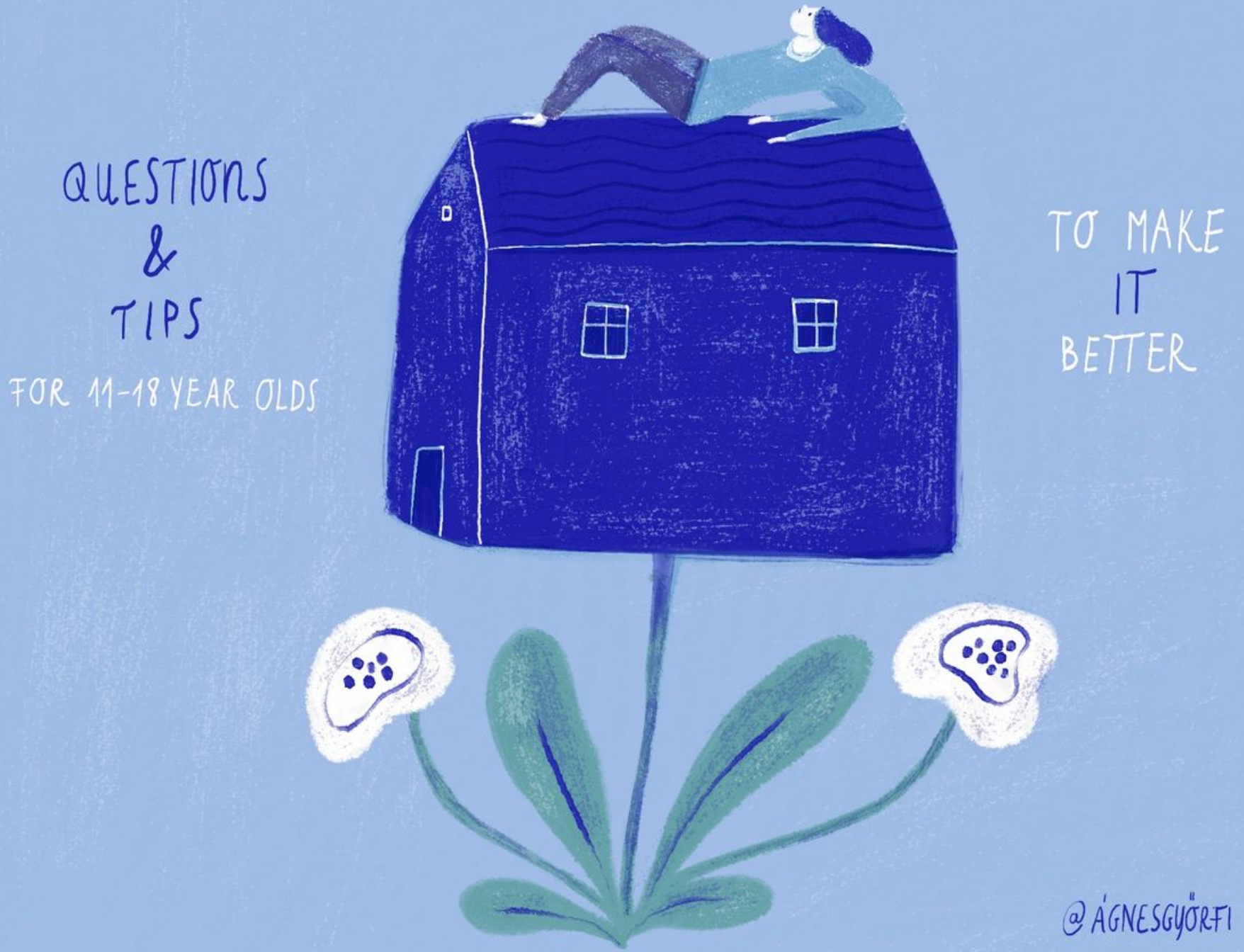

Figure 1

Logo of the project in English 


\section{\#MARADJOTTHON \\ Te hagy binod?}
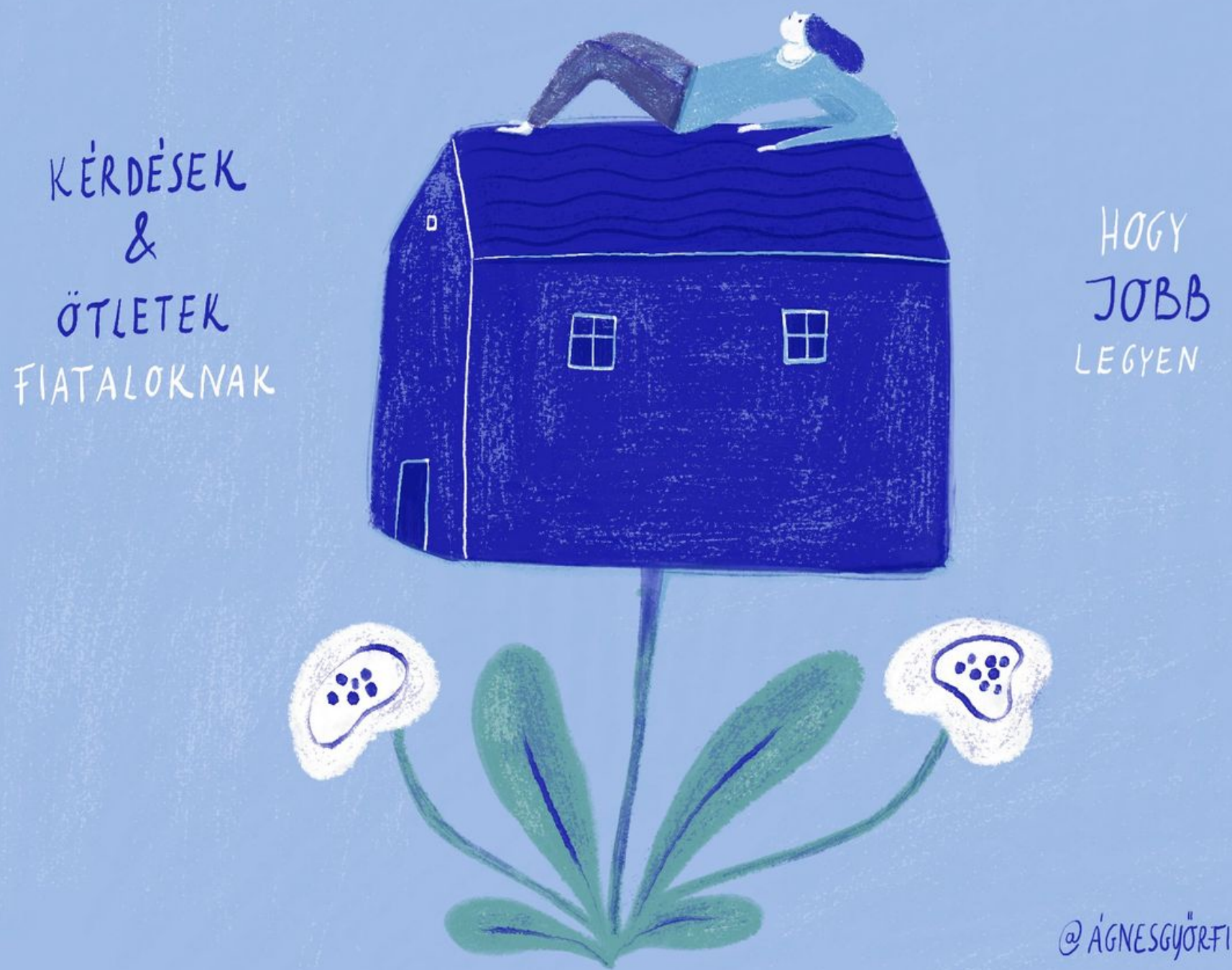

Figure 2

Logo of the project in Hungarian 


\section{\# BLIJFTHUIS}

Hoe gaat het met fe?

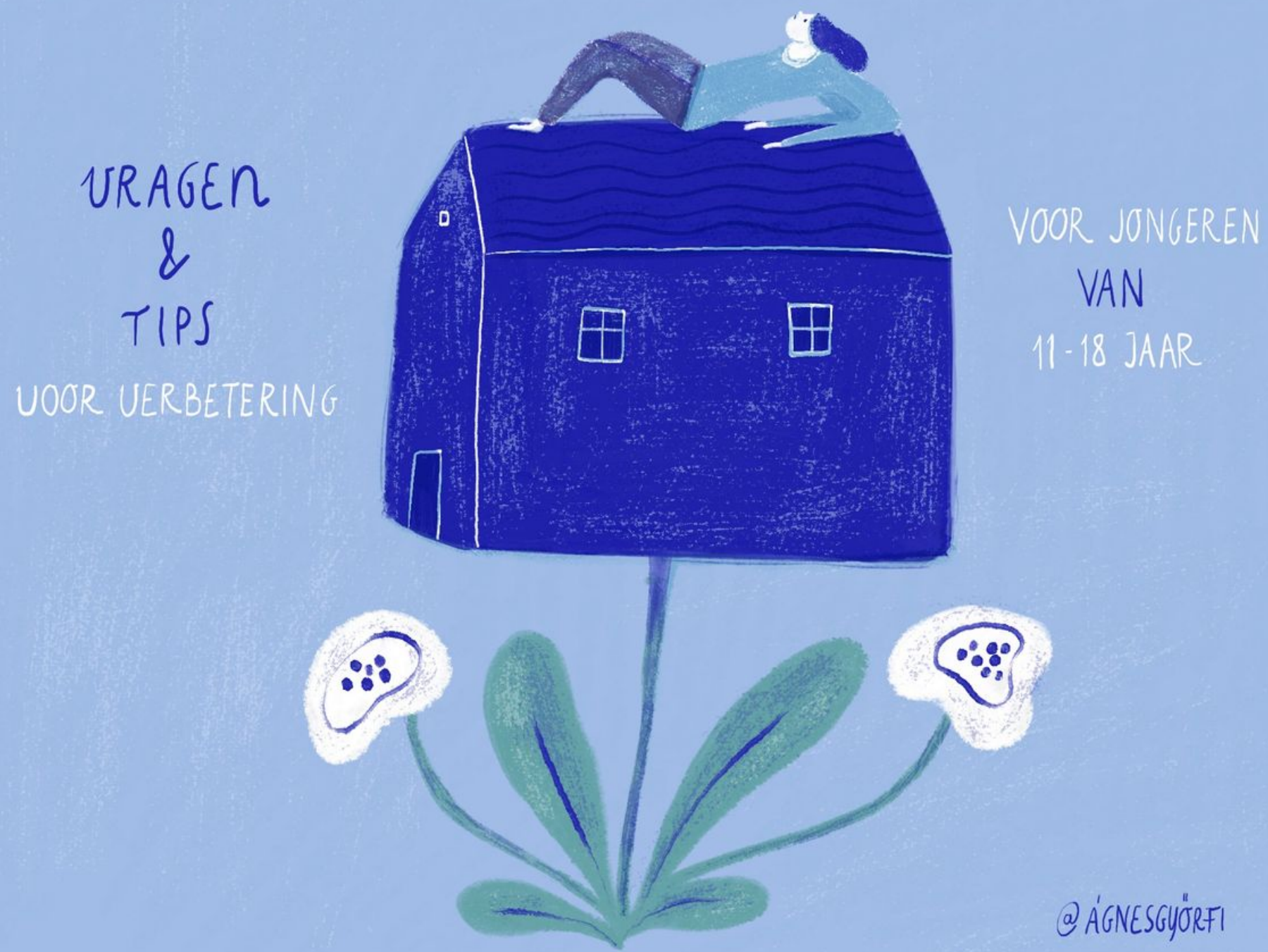

Figure 3

Logo of the project in Dutch 

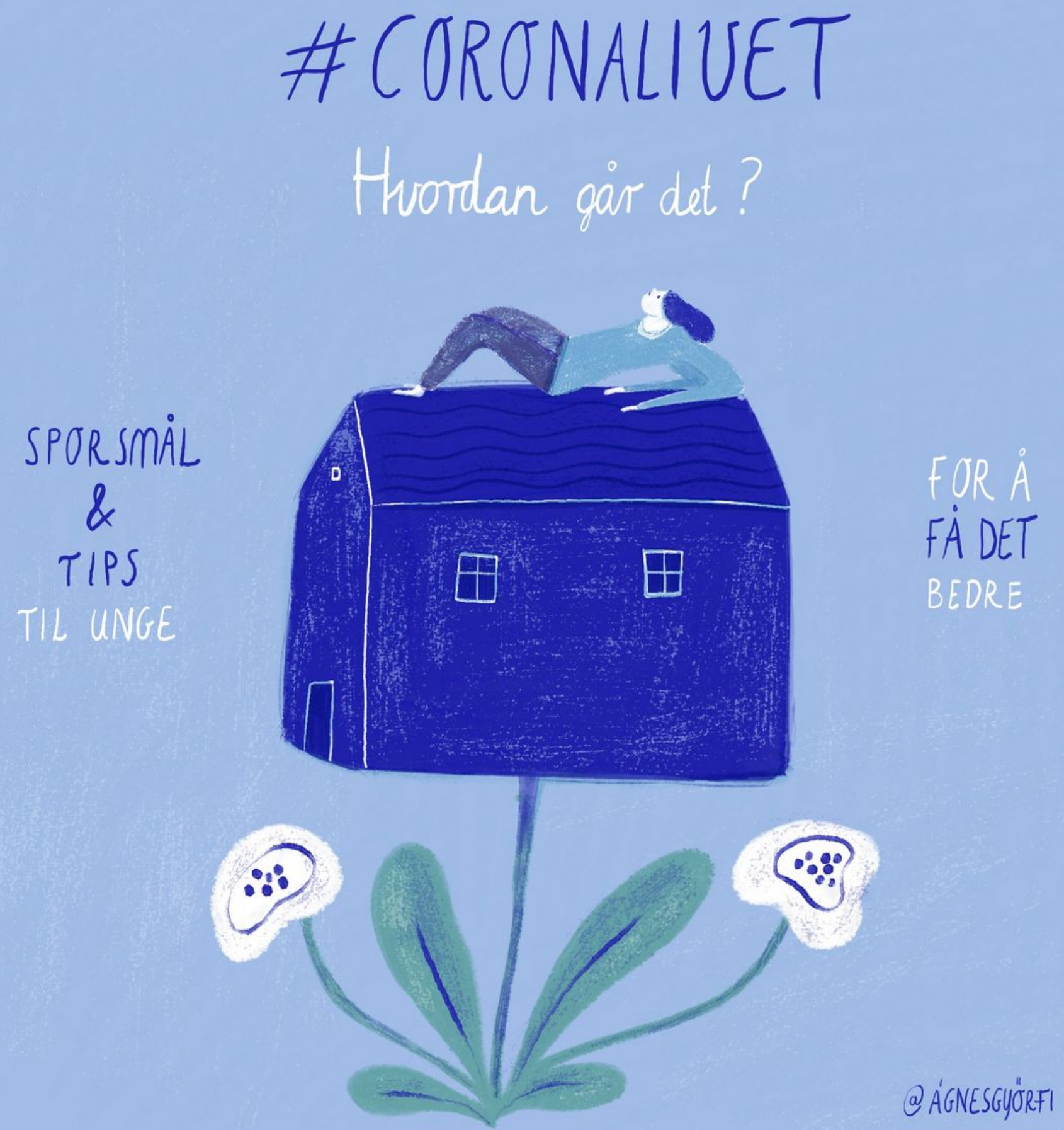

Figure 4

Logo of the project in Norwegian

\section{Supplementary Files}

This is a list of supplementary files associated with this preprint. Click to download. 
- SPIRITChecklistdownload8Jan13BALAZS.doc 